NASA TECHNICAL NOTE

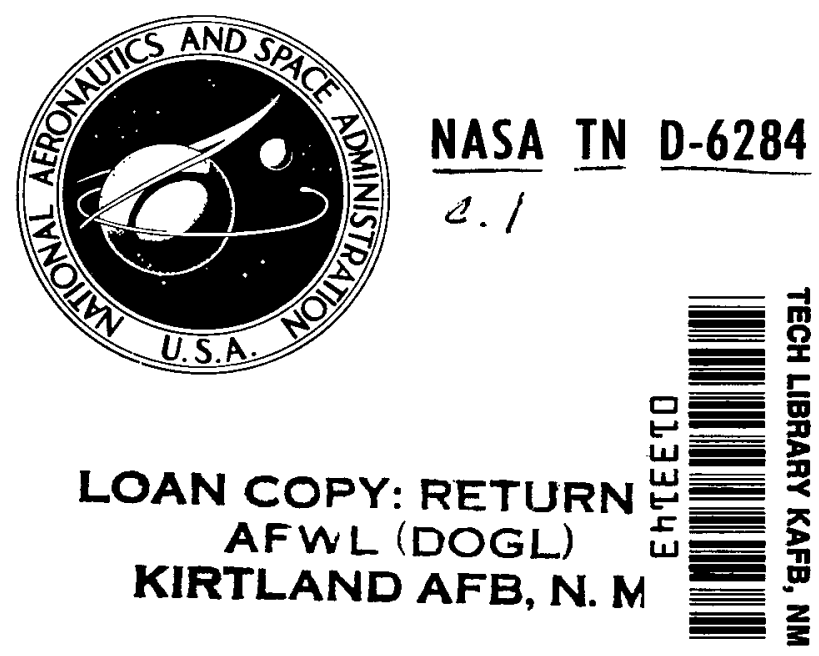

\title{
A GENERAL FORMULA \\ FOR THE DECAY LIFETIMES \\ OF THE STARFISH ELECTRONS
}

by

E. G. Stassinopoulos

Goddard Space Flight Center

and

P. Verzariu

Johns Hopkins University

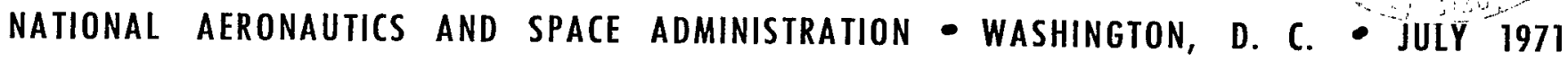


1. Report No.

INASA TN D-6284

2. Government Accession No.

4. Title and Subtitle

A General Formula for the Decay Lifetimes of the Starfish Electrons

7. Author(s)

E. G. Stassinopoulos and P. Verzariu

9. Performing Organization Name and Address

Goddard Space Flight Center

Greenbelt, Maryland 20771

12. Sponsoring Agency Name and Address

National Aeronautics and Space Administration

Washington, D.C. 20546
3. Recipient's Catalog No.

5. Report Date

July 1971

6. Performing Organization Code

8. Performing Organization Report No. G-1016

10. Work Unit No.

11. Contract or Grant No.

13. Type of Report and Period Covered

Technical Note

14. Sponsoring Agency Code

15. Supplementary Notes

This work was supported in part by the Department of the Navy under contract N00017-62-C-0604.

16. Abstract

A treatment based on the analysis of data from Satellite $196338 \mathrm{C}$ has been developed to calculate the decay lifetimes of the artificial electrons produced by the Starfish nuclear explosion. The treatment makes use of experimental data and describes the decay lifetime $\tau$ in the form of a continuum in $B L E$-space. The results are valid over the entire inner zone of the trapped radiation belt. Reference maps of constant $\tau$ contours in $B L-, B E$-, and $L E$-space have been constructed and are discussed.

17. Key Words Suggested by Author

Artificial Electrons

Decay Lifetimes

Electron Decay

19. Security Classif. (of this report)

20. Security Classif. (of this page)

Unclassified

Unclassified
18. Distribution Statement

Unclassified-Unlimited

21. No. of Pages

$11 \quad 3.00$
22. Price *

*For sale by the National Technical Information Service, Springfield, Virginia 22151 
CONTENTS

INTRODUCTION $\ldots \ldots \ldots \ldots \ldots \ldots \ldots \ldots \ldots \ldots \ldots \ldots \ldots \ldots \ldots \ldots \ldots$

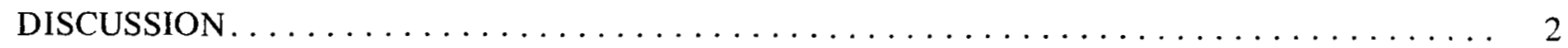

DATA PROCESSING $\ldots \ldots \ldots \ldots \ldots \ldots \ldots \ldots \ldots \ldots \ldots \ldots \ldots \ldots \ldots \ldots \ldots$

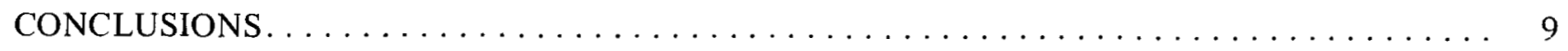

ACKNOWLEDGMENTS $\ldots \ldots \ldots \ldots \ldots \ldots \ldots \ldots \ldots \ldots \ldots \ldots \ldots \ldots \ldots$

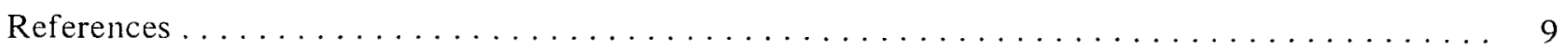




\title{
A GENERAL FORMULA FOR THE DECAY LIFETIMES OF THE STARFISH ELECTRONS*
}

\author{
by \\ E. G. Stassinopoulos \\ Goddard Space Flight Center \\ and \\ P. Verzariu \\ Applied Physics Laboratory, Johns Hopkins University
}

\section{INTRODUCTION}

Seven artificial radiation belts have been made by the explosion of high-altitude nuclear devices since 1958. Of these, the Starfish event of July 9, 1962, a low-latitude nuclear explosion, produced an intense region of trapped artificial electrons with very long lifetimes.

The spatial and temporal characteristics of the artificial radiation zone have received considerable treatment in the literature, and the decay lifetimes for the injected electrons have been discussed by several authors (Van Allen, 1964; Cladis et al., 1965; Bostrom and Williams, 1965; Brown, 1966; Mcllwain, 1966; Paulikas et al., 1967; Beall et al., 1967; Pfitzer, 1968; Bostrom et al., 1970). The picture that emerges is that of a fast decay at very low $L$ values ( $L \leqslant 1.2$ ), which is consistent with the predictions of atmospheric scattering theory (Walt, 1964). Short lifetimes also occur at the outer edge of the inner radiation zone in the slot region. For the intermediate $L$ values, the decay is slower, with longest lifetimes occurring at $L \sim 1.4$. At low $L$ values $(1.15 \leqslant L \leqslant 1.4$ ), a $B$-dependence is also observed (Beall et al., 1967).

In the years following 1962. computer programs were developed at GSFC to estimate the flux decay of artificially injected electrons and predict the radiation hazards to which satellites would be exposed (Stassinopoulos, 1965, 1967). The decay lifetimes used in the calculation of orbit-integrated, vehicle-encountered particle fluxes were based on fragmentary published data, and as such they were restricted and not very accurate (Stassinopoulos, 1965). In this paper a unified treatment of the decay of the artificial electrons in the inner zone is presented, with the decay lifetime $\tau$ expressed as a continuous function of field strength $B$, magnetic shell parameter $L$, and energy $E$. The data used in the analysis is essentially taken from a single satellite, the $196338 \mathrm{C}, \uparrow$ and covers the time span from

*This work was supported in part by the Department of the Navy under contract N00017-62-C-0604.

$\uparrow$ Designed and built by the Applied Physics Laboratory, Johns Hopkins University. 
launch, September 28, 1963, to December 1968, when, it is felt, the energy channels of the satellite measured essentially the radiation of the natural background (Bostrom et al., 1970). A description of the satellite and its instrumentation can be found in the literature (Williams and Smith, 1965; Bostrom et al., 1967; Beall et al., 1967).

\section{DISCUSSION}

In order to facilitate the handling of the problem, the following simplifying assumptions are made:

(1) The decay lifetime $\tau$ remains constant in time.

(2) Solar-cycle, diurnal, and secular-change effects can be neglected.

(3) The decay of the Starfish electrons can be approximated by an exponential form.

(4) The $B$-dependence of $\tau$ does not extend beyond $L \geqslant 1.40$.

Assumption (3) is justified by the 1963 38C data; assumption (4) is supported by comparison with OGO data, which measures a wider range of equatorial pitch angles than does 38C (Pfitzer, 1968; Pfitzer and Winckler, 1968).

When the data is ordered in terms of the variable $L$, three distinct regions emerge (Figure 1 ), each identified by a characteristic functional dependence of $\tau$ on the parameters $B, L$, and $E$. We denote

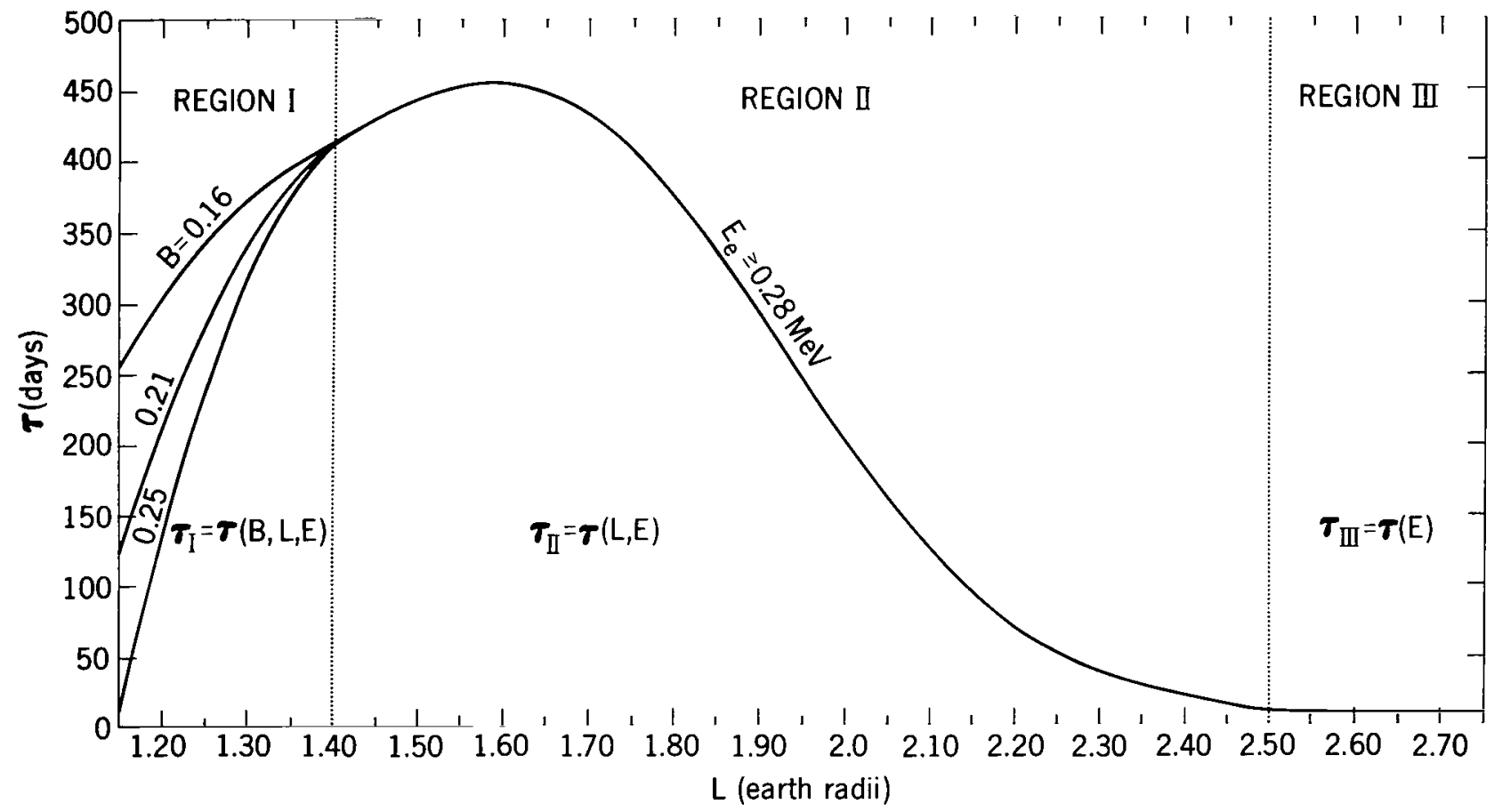

Figure 1-Domains of functional dependence of the decay lifetime $\tau$ on $B, L$, and $E$ for $E_{e} \geqslant 0.28 \mathrm{MeV}$. 
the three regions as I, II, and III. In region I, which extends from $L=1.15$ to $L=1.40$ (for all electron energies), $\tau$ is a function of all the variables: $B, L$, and $E$. The $B$-dependence of the decay constant has been previously discussed by Beall et al. (1967), and it appears to become indeterminate for $L \geqslant 1.4$. Consequently, in our treatment we will take $\tau$ in region II to depend only upon $L$ and $E$. Region II extends from $L>1.4$ to approximately $L \sim 2.3$, with the latter boundary being dependent on energy. Curves obtained for region II from the $38 \mathrm{C}$ data when $\tau$ is plotted versus $E$ for all three channels at given $L$ values suggest that the high-energy electrons exhibit the most rapid decay and that at the time of the 1963 38C measurements almost no artificial electrons with energies greater than $2 \mathrm{MeV}$ remained in regions where $L \geqslant 1.8$. This is in general agreement with currently prevailing opinion* (Pfitzer, 1968). Thus, in the generation of the $\tau$ versus $E$ plots for region II $(1.4<L \leqslant 2.3$ ), no data from the $196338 \mathrm{C}$ channel $3\left(E_{e} \geqslant 2.4 \mathrm{MeV}\right)$ were used; instead, the $\tau$-dependence was extended linearly to the higher energies, with only data obtained from channels $1\left(E_{e} \geqslant 0.28 \mathrm{MeV}\right)$ and $2\left(E_{e} \geqslant 1.2\right.$ $\mathrm{MeV}$ ) being used. This is consistent with the derivation of the decay lifetimes obtained by Beall et al. (1967) and reflects the uncertainty in the channel 3 data due to background proton contamination. At the higher $L$ values $(L>1.8)$ in this region, the data were adjusted to fit reported measurements (Van Allen, 1966; Mcllwain, 1966; Brown, 1966).

Finally, in region III, which includes all $L$-space beyond about 2.3 , the decay lifetime was taken to be only a function of energy. In this region, $\tau$ is typically of the order of one month or less and will be neglected in this treatment. Figure 1 outlines the domains of the regions discussed above for electrons with $E_{e} \geqslant 0.28 \mathrm{MeV}$ and indicates the dependence of $\tau$ on the variables appropriate to each domain.

In the formulation of this problem, a four-dimensional space is considered in which the decay lifetime $\tau$ is a continuous function of the variables $B, L$, and $E$. The boundaries beyond which computation of $\tau$ is discontinued are:

(1) The equatorial envelope, as defined by Mcllwain (1961).

(2) The radiation-belt terminus, designated as the constant-electron-intensity contour of one particle per square centimeter per second, for trapped electrons with energies greater than $0.5 \mathrm{MeV}$, as given by Vette et al. (1966).

(3) The surface $\tau=0$.

It is assumed that the terminus is independent of time and energy in $B L$-space, since any slight changes in its position due to energy dependence or secular variations do not affect the derivations and conclusions presented in this treatment. The four-dimensional space is then subdivided into volume elements such that within each volume the parameter $\tau$ may be linearized for each of its variables (i.e., all partial derivatives of $\tau$ are constant).

Since the decay constant depends mainly on the magnetic shell parameter $L$, appropriate increments in $L$ have to be taken so as to preserve the linearity requirement for the derivatives of $\tau$ within each volume element. Thus, region I is subdivided into $11 \mathrm{~L}$-intervals and region II into $19 L$-intervals.

*J. I. Vette, private communication, 1970. 

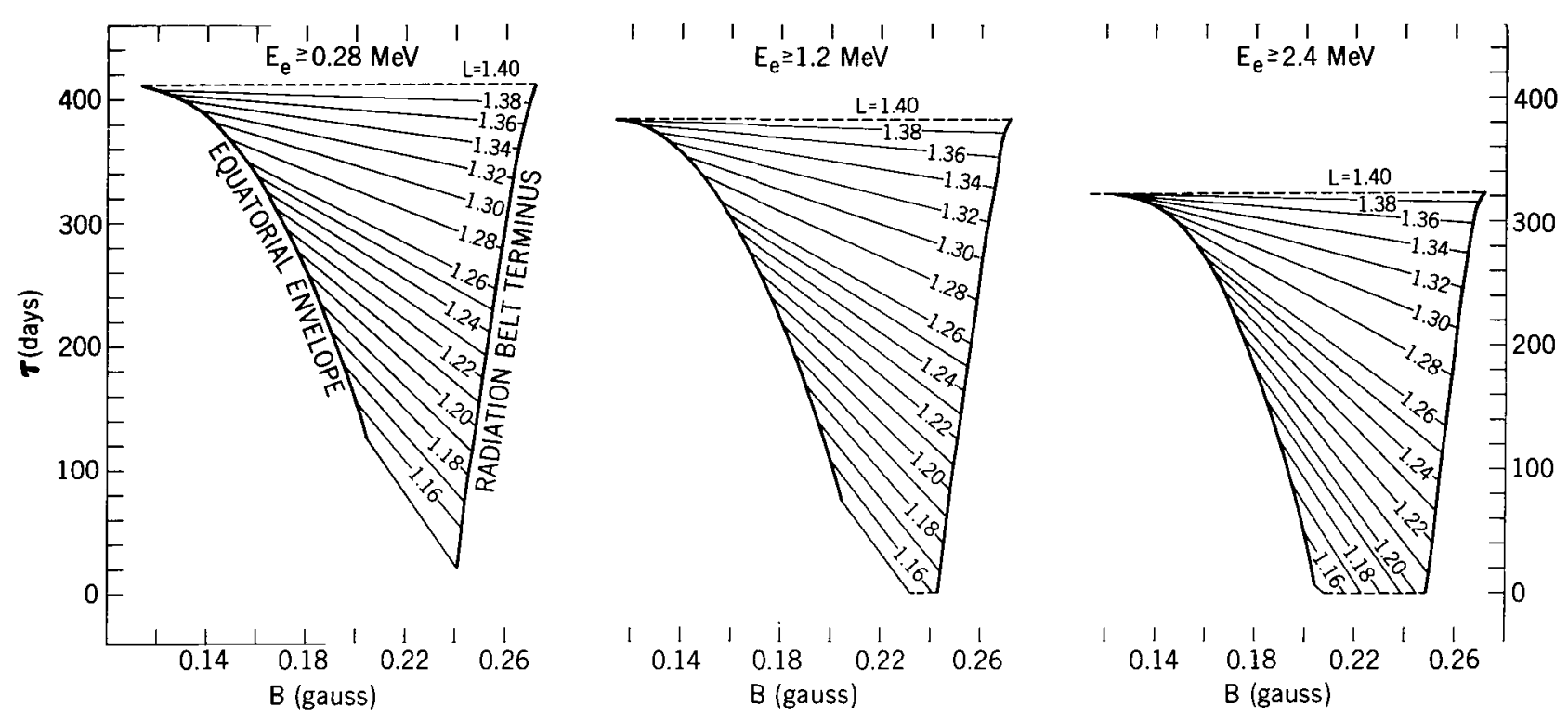

Figure 2 -Decay lifetimes in region $\mid(1.15 \leqslant L \leqslant 1.4)$ showing the $B$ and $L$ dependence of $\tau$ for the $196338 \mathrm{C}$ satellite energy channels.

Figure 2 shows the dependence of $\tau$ on the variables in region I for the three energy channels of satellite 1963 38C. In the next two figures, several cross sections of the $\tau$ domain in region I are plotted. Figure 3 shows $B-L$ cross sections for $E_{e} \geqslant 0.25,0.5,1$, and $3 \mathrm{MeV}$; Figure 4 shows several $B-E$ cross sections at four discrete values of $L$. In both figures, the dependence of $\tau$ on $B$ at these low values of $L$ is clearly evident. Figure 5 shows the dependence of $\tau$ on $L$ and $E$ in region II. The slowest decay in this treatment occurs at $L \sim 1.6$ for $E_{e} \sim 0.3 \mathrm{MeV}$. The peak in the $\tau$ contours gradually drifts toward $L \sim 1.4$ at the higher integral energies. Curves for $\tau$ are not plotted for $E_{e}<0.2 \mathrm{MeV}$ because there is evidence that the low-energy component $\left(E_{e} \sim 0.1 \mathrm{MeV}\right)$ of the integral electron flux does not manifest a perceptible decay (Pfitzer, 1968; Pfitzer and Winckler, 1968).

\section{DATA PROCESSING}

A generalized treatment for all three variables as they pertain to region I will be given here. The same treatment, appropriately modified to deal with only two variables, applies to region II. In general,

$$
\tau=\tau(B, L, E) \text {. }
$$

The following relations then hold within each volume element:

$$
\begin{gathered}
\tau=\kappa(B, L) E+\lambda(B, L), \quad \kappa=\frac{\partial \tau}{\partial E}=\mu(L) B+\nu(L), \\
\nu=\gamma L+\eta, \quad \mu=\frac{\partial^{2} \tau}{\partial B \partial E}=\alpha L+\delta, \\
\alpha=\frac{\partial^{3} \tau}{\partial L \partial B \partial E},
\end{gathered}
$$



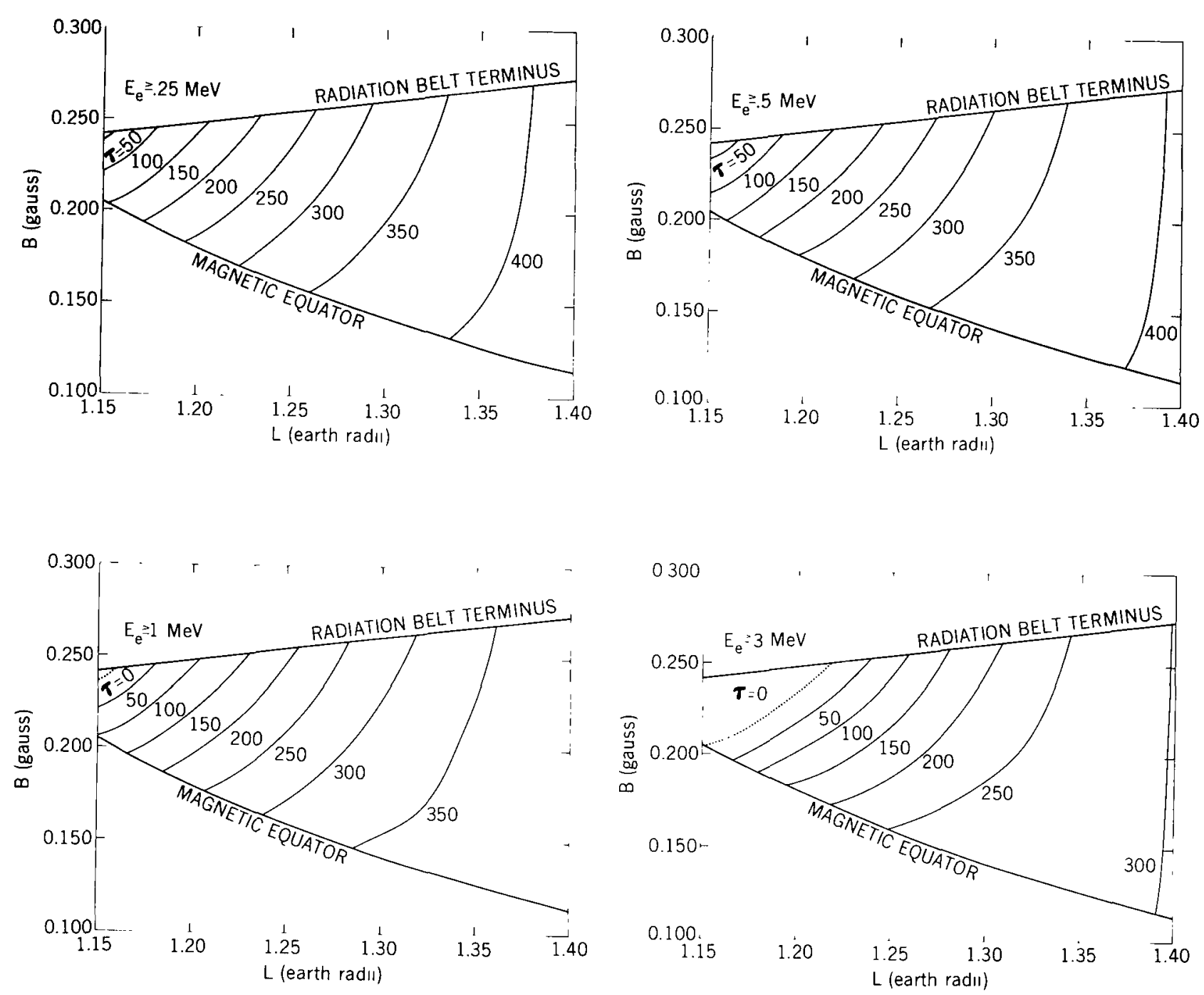

Figure $3-B L$ cross sections of the $\tau$ domain in region $I(1.15 \leqslant L \leqslant 1.4)$ for several integral energies.

and

$$
\begin{array}{ll}
\lambda=\pi(L) B+\sigma(L), & \sigma=\epsilon L+\phi, \\
\pi=\frac{\partial \lambda}{\partial B}=\beta L+\zeta, & \beta=\frac{\partial^{2} \lambda}{\partial L \partial B} .
\end{array}
$$

Combining the expressions yields a general function for the mean lifetime within the volume element:

$$
\tau(B, L, E)=\alpha B L E+\beta B L+\gamma L E+\delta B E+\epsilon L+\zeta B+\eta E+\phi .
$$

The coefficients of the variables $B, L$, and $E$ form a matrix and are found for a particular volume element by successively linearizing all the derivatives of $\tau$. For those intermediate volume elements for 

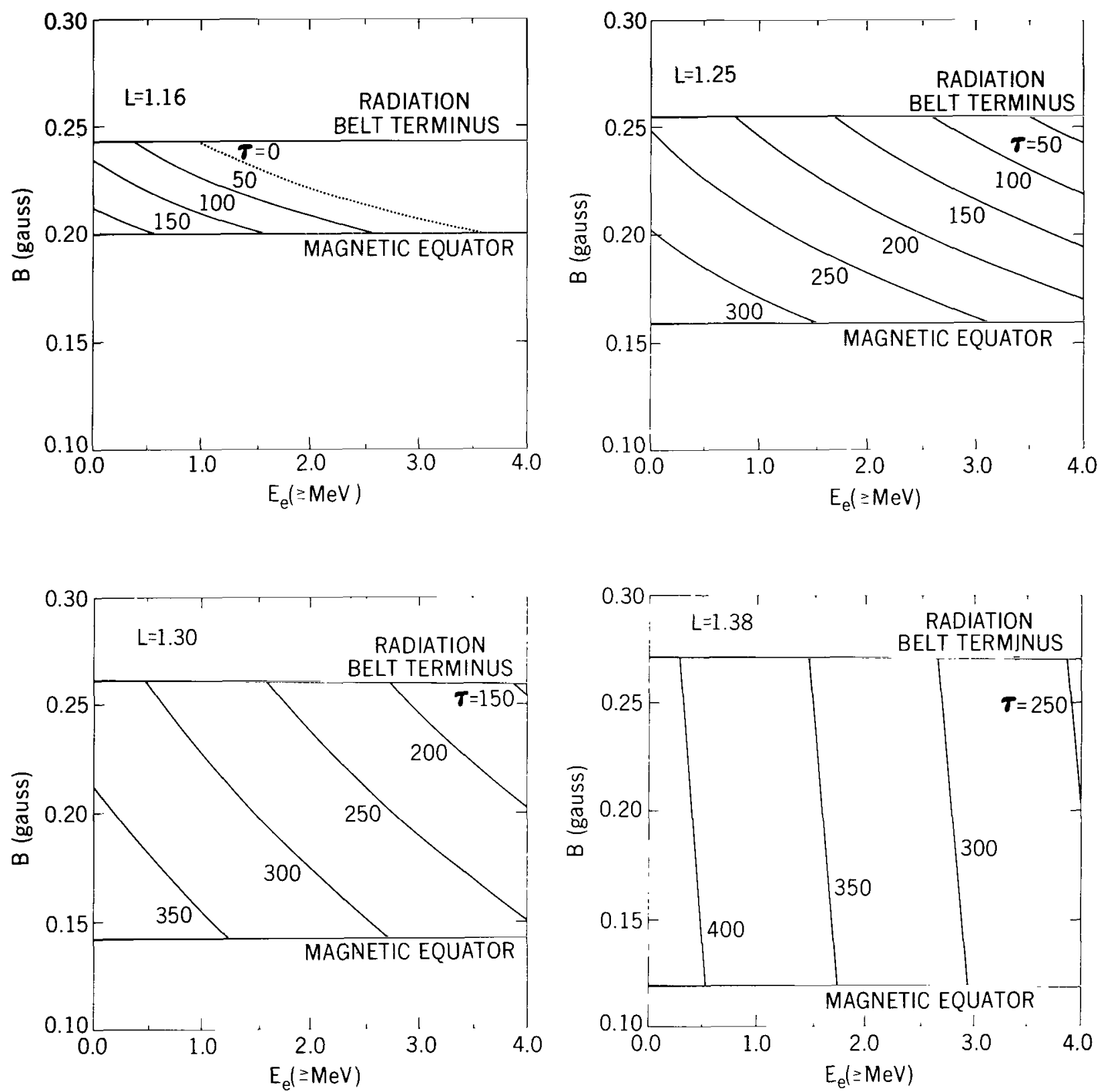

Figure $4-B E$ cross sections of the $\tau$ domain in region $I(1.15 \leqslant L \leqslant 1.4)$ at several $L$ values.

which coefficients cannot be determined due to sparse or insufficient data points, the known coefficient values from adjacent bracketing volume elements are linearly extrapolated, so as to match all slopes at the respective boundaries. Thus, a continuous functional relationship between the decay lifetime $\tau$ and its variables $B, L$, and $E$ is generated for the inner zone. Table 1 gives the values of the 30 sets of coefficients in the respective $L$ ranges. In Table 2 the predicted and measured counting rates of channels 1 and 2 are compared at selected $L$ values, for the period from January 1964 to December 1964. 


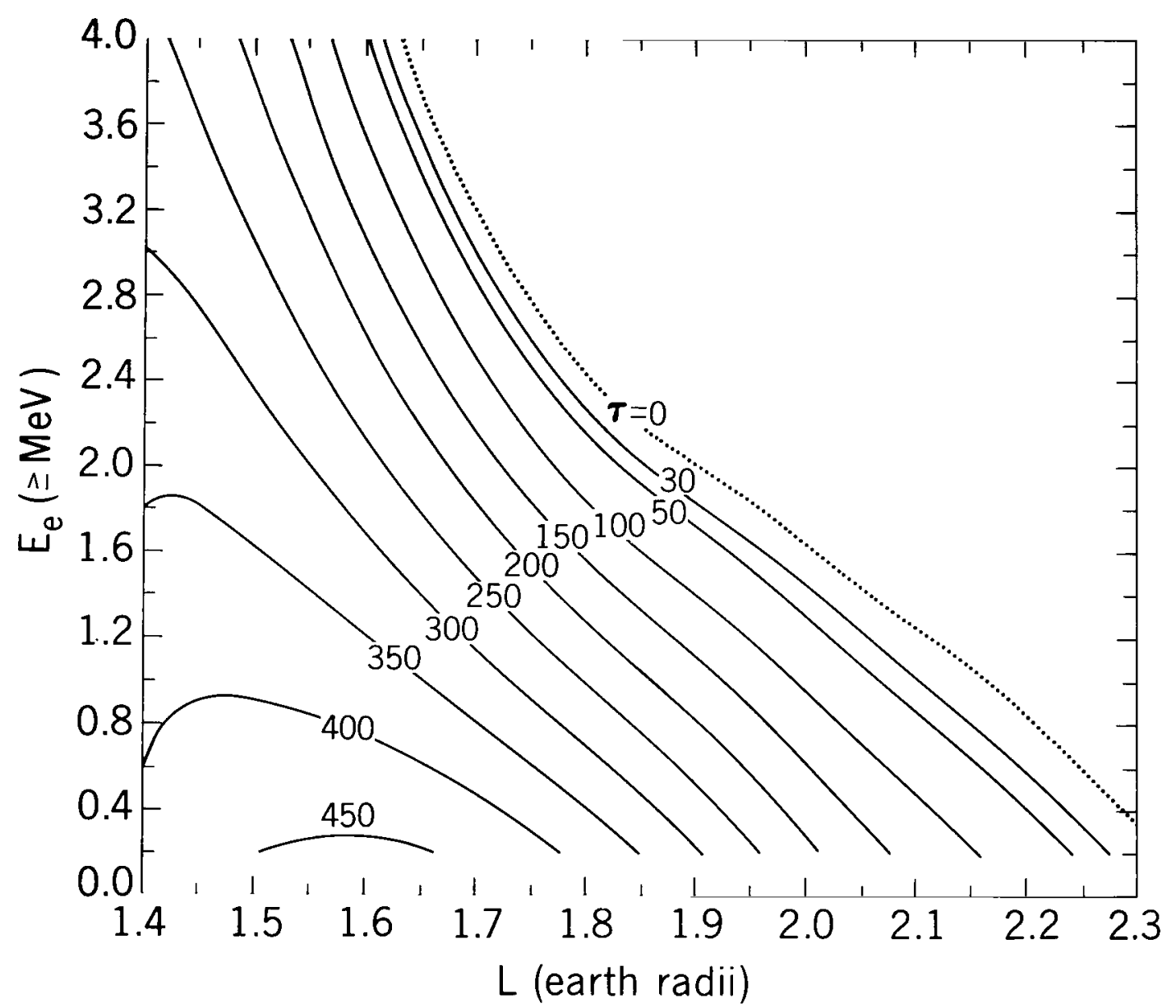

Figure 5-Decay lifetimes in region $\|(1.4 \leqslant L \leqslant 2.3)$ for integral energies above $0.2 \mathrm{MeV}$.

Table 2-Comparison of measured and predicted counting rates, January 1964-December 1964.

\begin{tabular}{|c|c|c|c|c|c|c|}
\hline \multirow{2}{*}{$L$} & \multicolumn{2}{|c|}{$\mathrm{CPS}(E \geqslant .28 \mathrm{MeV})$} & \multirow{2}{*}{$\begin{array}{c}\% \\
\text { Difference }\end{array}$} & \multicolumn{2}{|c|}{$\mathrm{CPS}(E \geqslant 1.2 \mathrm{MeV})$} & \multirow{2}{*}{$\begin{array}{c}\% \\
\text { Difference }\end{array}$} \\
\hline & Measured & Predicted & & Measured & Predicted & \\
\hline 1.2 & 256 & 261 & $\sim 2.0$ & 226 & 229 & $\sim 1.3$ \\
\hline 1.4 & 416 & 413 & $\sim 0.7$ & 372 & 375 & $\sim 0.8$ \\
\hline 1.6 & 320 & 450 & $\sim 40.6$ & 302 & 349 & $\sim 15.6$ \\
\hline 1.8 & 251 & 371 & $\sim 47.8$ & - & - & _ \\
\hline
\end{tabular}


Table 1-Coefficients of the lifetime function.

\begin{tabular}{|c|c|c|c|c|c|c|c|c|c|}
\hline $\begin{array}{l}\text { Volume } \\
\text { Element }\end{array}$ & $L$-Range & $\alpha$ & $\beta$ & $\gamma$ & $\delta$ & $\epsilon$ & $\xi$ & $\eta$ & $\phi$ \\
\hline 1 & $1.15-1.16$ & 6714.00 & 24830.00 & -1236.00 & -8529.46 & -4439.40 & -31067.70 & 1532.88 & 5778.45 \\
\hline 2 & $1.16-1.17$ & 6322.00 & 19470.00 & -1150.00 & -8074.70 & -2174.50 & -24849.90 & 1433.12 & 3151.15 \\
\hline 3 & $1.17-1.18$ & 8323.00 & 15000.00 & -1579.00 & -10415.91 & -1500.00 & -19620.00 & 1935.05 & 2362.00 \\
\hline 4 & $1.18-1.20$ & 6584.50 & 12080.00 & -1176.50 & -8364.48 & -963.30 & -16174.40 & 1460.10 & 1729.36 \\
\hline 5 & $1.20-1.25$ & 4203.60 & 11854.00 & -776.20 & -5507.40 & -1070.74 & -15903.20 & 979.74 & 1858.29 \\
\hline 6 & $1.25-1.28$ & 3520.67 & 10383.30 & -657.13 & -4653.73 & -878.33 & -14064.80 & 830.91 & 1617.78 \\
\hline 7 & $1.28-1.30$ & 2770.00 & 9020.00 & -520.80 & -3692.88 & -863.25 & -12319.80 & 656.40 & 1598.48 \\
\hline 8 & $1.30-1.32$ & 1812.00 & 8030.00 & -406.30 & -2447.48 & -820.80 & -11032.80 & 507.55 & 1543.29 \\
\hline 9 & $1.32-1.34$ & 1485.50 & 7045.00 & -341.70 & -2016.50 & -506.20 & -9732.60 & 422.28 & 1128.02 \\
\hline 10 & $1.34-1.38$ & 578.00 & 5634.15 & -139.25 & -800.45 & -484.33 & -7842.06 & 151.00 & 1098.71 \\
\hline 11 & $1.38-1.40$ & 140.50 & 3346.70 & -18.00 & -196.70 & -216.95 & -4685.38 & -16.33 & 729.73 \\
\hline 12 & $1.40-1.425$ & 0 & 0 & -258.88 & 0 & 560.00 & 0 & 320.90 & -358.00 \\
\hline 13 & $1.425-1.45$ & 0 & 0 & -292.00 & 0 & 400.00 & 0 & 368.10 & -130.00 \\
\hline 14 & $1.45-1.475$ & 0 & 0 & -276.00 & 0 & 320.00 & 0 & 344.90 & -14.00 \\
\hline 15 & $1.475-1.51$ & 0 & 0 & -297.14 & 0 & 200.00 & 0 & 376.09 & 163.00 \\
\hline 16 & $1.51-1.55$ & 0 & 0 & -337.75 & 0 & 175.00 & 0 & 437.40 & 200.75 \\
\hline 17 & $1.55-1.60$ & 0 & 0 & -422.22 & 0 & 160.00 & 0 & 568.33 & 224.00 \\
\hline 18 & $1.60-1.625$ & 0 & 0 & -425.20 & 0 & 40.00 & 0 & 573.10 & 416.00 \\
\hline 19 & $1.625-1.65$ & 0 & 0 & -419.32 & 0 & -80.00 & 0 & 563.55 & 611.00 \\
\hline 20 & $1.65-1.70$ & 0 & 0 & -358.34 & 0 & -220.00 & 0 & 462.93 & 842.00 \\
\hline 21 & $1.70-1.75$ & 0 & 0 & -321.38 & 0 & -400.00 & 0 & 400.10 & 1148.00 \\
\hline 22 & $1.75-1.775$ & 0 & 0 & -241.24 & 0 & -520.00 & 0 & 259.85 & 1358.00 \\
\hline 23 & $1.775-1.82$ & 0 & 0 & -147.78 & 0 & -644.44 & 0 & 93.96 & 1578.89 \\
\hline 24 & $1.82-1.85$ & 0 & 0 & 0 & 0 & -766.67 & 0 & -175.00 & 1801.33 \\
\hline 25 & $1.85-1.87$ & 0 & 0 & 75.00 & 0 & -850.00 & 0 & -313.75 & 1955.50 \\
\hline 26 & $1.87-1.95$ & 0 & 0 & 198.41 & 0 & -962.50 & 0 & -544.53 & 2165.88 \\
\hline 27 & $1.95-2.00$ & 0 & 0 & 222.60 & 0 & -980.00 & 0 & -591.70 & 2200.00 \\
\hline 28 & $2.00-2.05$ & 0 & 0 & 217.76 & 0 & -900.00 & 0 & -582.30 & 2040.00 \\
\hline 29 & $2.05-2.10$ & 0 & 0 & 212.18 & 0 & -740.00 & 0 & -570.86 & 1710.00 \\
\hline 30 & $2.10-2.30$ & 0 & 0 & 69.28 & 0 & -600.00 & 0 & -270.49 & 1418.00 \\
\hline
\end{tabular}




\section{CONCLUSIONS}

When the model presented in this treatment is used, the following should be considered:

(1) Decay lifetimes should not be extrapolated backward too close to the epoch of the nuclear event because the initial decay (first few weeks) is considerably faster than at the later times considered in the present analysis.

(2) The estimated maximum value of the error for the calculated $\tau$ is about 2 percent at intermediate $L$ values $(1.2 \leqslant L \leqslant 1.5)$. At higher $L$ values $(L \geqslant 1.6)$ and at low $L$ values $(L<1.2)$, the error increases to about 30 percent on the average.

(3) The functional dependence of $\tau$ on energy has been derived through use of integral energy channels and may differ from decay constants obtained from differential energy measurements.

(4) At low energies $\left(E_{e} \leqslant 0.20 \mathrm{MeV}\right)$, the validity of the energy dependence of $\tau$ becomes marginal. There is evidence that electrons of these energies do not manifest a decay (Pfitzer, 1968; Pfitzer and Winckler, 1968) but that they are mainly part of the natural component of the radiation belt. At the higher integral energies, it is felt that the treatment should not be extrapolated beyond $E_{e} \geqslant 5 \mathrm{MeV}$.

\section{ACKNOWLEDGMENTS}

The authors wish to thank Dr. J. I. Vette for many stimulating discussions regarding this study. Discussions with Dr. C. O. Bostrom and Dr. S. M. Krimigis are also gratefully acknowledged. The longevity of satellite 1963-38C, designed and built at the Applied Physics Laboratory, Johns Hopkins University, has made this study possible.

\footnotetext{
Goddard Space Flight Center

National Aeronautics and Space Administration

Greenbelt, Maryland, November 9, 1970 $188-36-51-05-51$
}

\section{REFERENCES}

Beall, D. S., Bostrom, C. O., and Williams, D. J., "Structure and Decay of the Starfish Radiation Belt, October 1963 to December 1965,"J. Geophys. Res. 72:3403-3424, 1967.

Bostrom, C. O., and Williams, D. J., "Time Decay of the Artificial Radiation Belt," J. Geophys. Res. 70: $240-242,1965$.

Bostrom, C. O., Kohl, J. W., and Williams, D. J., "The February 5, 1965 Solar Proton Event, 1. Time History and Spectrums Observed at 1100 Kilometers," J. Geophys. Res. 72:4487-4495, 1967.

Bostrom, C. O., Beall, D. S., and Armstrong, J. C., "Time History of the Inner Radiation Zone, October 1963 to December 1968,"J. Geophys. Res. 75:1246-1256, 1970. 
Brown, W. L., "Observations of the Transient Behavior of Electrons in the Artificial Radiation Belts," in Radiation Trapped in the Earth's Magnetic Field pp. 610-633, Astrophysics and Space Science Library, Vol. 5, Dordrecht-Holland: D. Reidel Publishing Company, 1966.

Cladis, J. B., Davidson, G. T., Francis, W. E., Newkirk, L. L., Tepley, L. R., Walt, M., and Wentworth, R. C., "Search for Possible Loss Processes for Geomagnetically Trapped Particles," Defense Atomic Support Agency Report 1713, Defense Atomic Support Agency, Washington, D.C., 20305, December 1965.

McIlwain, C. E., "Coordinates for Mapping the Distribution of Magnetically Trapped Particles," J. Geophys. Res. 66:3681-3691, 1961.

McIlwain, C. E., "Measurements of Trapped Electron Intensities Made by the Explorer XV Satellite," in Radiation Trapped in the Earth's Magnetic Field pp. 593-609, Astrophysics and Space Science Library, Vol. 5, Dordrecht-Holland: D. Reidel Publishing Company, 1966.

Paulikas, G. A., Blake, J. B., and Freden, S. C., "Inner Zone Electrons in 1964 and 1965," J. Geophys. Res. 72: 2011-2020, 1967.

Pfitzer, K. A., "An Experimental Study of Electron Fluxes from $50 \mathrm{keV}$ to $4 \mathrm{MeV}$ in the Inner Radiation Belt," Univ. of Minnesota School of Physics and Astronomy Technical Report CR-123, University of Minuesota, Minneapolis, Minn., August 1968.

Pfitzer, K. A., and Winckler, J. R., "Experimental Observation of a Large Addition to the Electron Inner Radiation Belt After a Solar Flare Event," J. Geophys. Res. 73:5792-5797, 1968.

Stassinopoulos, E. G. " A Computer Program to Calculate Artificial Radiation Belt Decay Factors," NASA Technical Note D-2874, National Aeronautics and Space Administration, Washington, D.C., 1965.

Stassinopoulos, E. G., "Orbital Flux Integration Within the Subsynchronous Regions of the Geomagnetic Cavity," NASA Technical Memorandum X-55875, National Aeronautics and Space Administration, Washington, D.C., 1967.

Van Allen, J. A., "Lifetime of Geomagnetically Trapped Electrons of Several MeV Energy," Nature 203: 1006-1007, 1964.

Van Allen, J. A., "Spatial Distribution and Time Decay of the Intensities of Geomagnetically Trapped Electrons From the High Altitude Nuclear Burst of July 1962," in Radiation Trapped in the Earth's Magnetic Field pp. 575-592, Astrophysics and Space Science Library, Vol. 5, DordrechtHolland: D. Reidel Publishing Company, 1966.

Vette, J. I., Lucero, A. B., and Wright, J. A., "Models of the Trapped Radiation Environment, Vol. II: Inner and Outer Zone Electrons," NASA Special Publication 3024, National Aeronautics and Space Administration, Washington, D.C., 1966. 
Walt, M., "The Effects of Atmospheric Collisions on Geomagnetically Trapped Electrons," J. Geophys. Res. 69:3947-3958, 1964.

Williams, D. J., and Smith, A. M., "Daytime Trapped Electron Intensities at High Latitudes at 1100 Kilometers," J. Geophys. Res. 70: 541-556, 1965. 


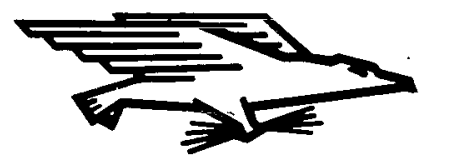

POSTAGE AND FEES PAID NATIONAL AERONAUTICS AND SPACE ADMINISTRATION

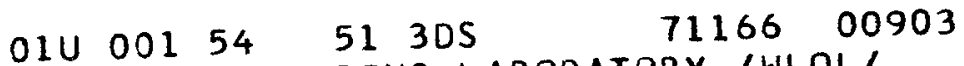

AIR FORCE WEAPONS LABORATORY /WLOL/

KIRTLAND AFB, NEW MEXICO 87117

ATT E. LOU BOWMAN, CHIEF, TECH. LIBRARY

"The aeronautical and space activities of the United States sball be conducted so as to contribute ... to the expansion of buman knowledge of phenzomena in the atmosphere and space. The Administration shall provide for the widest practicable and appropriate dissemination of information concerning its activities and the results thereof."

- National Aeronautics and Space ACt of 1958

\section{NASA SCIENTIFIC AND TECHNICAL PUBLICATIONS}

TECHNICAL REPORTS: Scientific and technical information considered important, complete, and a lasting contribution to existing knowledge.

TECHNICAL NOTES: Information less broad in scope but nevertheless of importance as a contribution to existing knowledge.

TECHNICAL MEMORANDUMS: Information receiving limited distribution because of preliminary data, security classification, or other reasons.

CONTRACTOR REPORTS: Scientific and technical information generated under a NASA contract or grant and considered an important contribution to existing knowledge.
TECHNICAL TRANSLATIONS: Information published in a foreign language considered to merit NASA distribution in English.

SPECIAL PUBLICATIONS: Information derived from or of value to NASA activities. Publications include conference proceedings, monographs, data compilations, handbooks, sourcebooks, and special bibliographies.

TECHNOLOGY UTILIZATION PUBLICATIONS: Information on technology used by NASA that may be of particular interest in commercial and other non-aerospace applications. Publications include Tech Briefs, Technology Utilization Reports and

Technology Surveys.

Details on the availability of these publications may be obtained from:

SCIENTIFIC AND TECHNICAL INFORMATION OFFICE

NATIONAL AERONAUTICS AND SPACE ADMINISTRATION Washington, D.C. 20546 